\begin{tabular}{ccc}
\hline & International Journal of Engineering \& Technology, $7(2.13)(2018) 210-219$ \\
SPC & International Journal of Engineering \& Technology \\
\hline
\end{tabular}

\title{
The new generation of winter recreational and sports facilities on artificial relief in cities
}

\author{
Marina Afonina *, Elena Shcherbina, Alevtina Balakina \\ Moscow State Construction University, Urban Construction and Environmental Safety Department26 Yaroslavskoye Shosse, \\ Moscow, Russian Federation 129337
}

\begin{abstract}
Nowadays we observe a rapid growth of various new and actively developing facilities for winter sports and recreation. This paper is aimed at analyzing the structure of these facilities and establishing the dependence of their public popularity on the design, technology, environmental and economic efficiency. The main research methods are monitoring of the chosen facilities, data collection and summarizing, classifying and description. The key procedures and results include on-site investigations of the facilities, sociological surveys of their popularity, definition of the factors that hamper their development, working out and testing a mathematical model of climatic influence on attendance. It is shown that despite the growing demand for new sports and recreational centers, most Russian cities do not have the necessary natural conditions (elevations, complex relief) to satisfy the requirements of the contemporary winter sports enthusiasts. To meet this demand, artificial constructions for mountain and cross-country skiing, snowboarding, tubing and skating are set in parks, residential areas and on specially designated territories. In building theses facilities, various designs, constructions and technologies are used, which are considered in detail in this paper. We provide examples of successful recreational centers on artificially engineered reliefs well-blended with the Moscow urban area. We make a conclusion about the advantages of constructing new facilities and the necessity to fit them harmoniously into the existing natural and man-made environment. Temporary constructions for sports and recreation have minimal impact on the environment. At the same time, they give room for experimenting with forms, materials, technologies; they are flexible, mobile and relevant for cities. We characterize such facilities as nature-and-technology compatible systems. Our findings can be useful for specialists in urban planning and development, ecology, sociology, economics, sports and recreational management.
\end{abstract}

Keywords: Sports Facilities; Footlights; Skiing Centers; Snowboarding Spots; Engineering Constructions; Tubing Tracks; City Events.

\section{Introduction}

In our country there was a time not so long ago when citizens could satisfy their need for outdoor winter recreation by means of natural resources - enjoy morning skiing in the nearby park or go sledding in the yard, etc. But the urban environment is changing, and nowadays in it not easy to find a place for sports and leisure activities close to your house. According to forecasts, the share of population of the Russian Federation regularly doing sports will reach $40 \%$ by 2020 [1], therefore an up-to-date sports and recreational facility should be located close to the place of residence, ideally within walking distance. The development of winter sports and appearance of new kinds of sport (freestyle skiing, aerial skiing, snowboarding, tubing, downhill skating, etc.) requires nonstandard solutions in designing the facilities and fitting them into the urban landscape. These requirements relate to different kinds of sports centers, including winter sports. A detailed overview of the existing facilities will eliminate future mistakes, optimize construction costs and make them architecturally attractive and environmentally compatible nature-and-technology systems [1].

Despite the growing demand for new facilities, most Russian cities lack the natural conditions (elevation differences and complex relief) for winter sports. The solution is building artificial facilities for cross-country and mountain skiing, snowboarding, tubing in parks and residential areas within a short distance from home; in Moscow these are Sokolniki and Gorky parks, Novoperedelkino, Sevastopolskiy, Nagorny districts, etc.
The relevance of new kinds of recreational and sports facilities leaves no doubt whatsoever; it is driven by both the popularity of healthy lifestyle and a wide variety and affordability of modern sports gear. There is an opportunity to use different planning and design concepts. Various city slopes have been created: "for beginners", "for fitness", etc. - downhill skiers and snowboarders use them regularly together with or instead of traditional skiing places. Besides, in the winter various temporary facilities appear: tubing tracks for children, snow parks and snowboarding spots with complex elements, top-class sports facilities for crosscountry and mountain skiing, snowboarding, downhill skating (ice cross downhill). Sportsmen's excellence and architects' imagination shape the tendencies for developing new facilities in the near future.

The variety of modern projects and completed constructions calls for their systemization with consideration of the reasons behind one or another design solution, which is the purpose of the paper. The suggested analysis allows improving the design process, finding new locations, evenly distributing recreational and sports facilities over a city's territory. All these measures are aimed to improve the citizens' quality of life.

\section{Methods description}

In general, in 2012 there were over 20 ski complexes within the Moscow metropolitan area, at the beginning of 2014 their number exceeded 30.Temporary local facilities are numerously built in the 
winter and are not always registered. First sports facilities with the use of artificial relief appeared due to sports enthusiasts' initiative. The combination of vigorous activity and efficient management allows these facilities to operate successfully over a number of years. These innovations have led to the development of a new line of construction. However, the city planning structure established in the Soviet period does not always give a good opportunity to create modern sports and recreational facilities varied in style and use. There is an objective need for using all available technological capabilities for placing new objects in the already existing man-made environment.

Using different scientific methods, we carried out an all-round research of the efficient use of expensive urban areas for the purposes of recreation and sport. This approach ensures optimal technology application for city planning with regard to technical, ecological, and economic efficiency, satisfying the needs of different social groups and maintaining the originality of each facility. The following works were performed:
1) On-site survey of the design of the recreation and sports facilities harmoniously fitting into the unified city system of recreation;

2) Sociological surveys reflecting the demand for the facilities [1];

3) Development and testing of a mathematical model of climatic factors influence on the attendance of the facilities [2];

4) Determination of the factors that hamper the development of the facilities [3], [4];

5) Analysis of the city planning and architectural analysis of winter sports facilities - mountain skiing, snowboarding, tubing and ice cross downhill [5- 8].

As a result, a first classification of winter sports facilities on manmade relief is developed. A typology of methods for relief alterations is suggested for recreation and sports permanent and temporary facilities (Fig. 1).

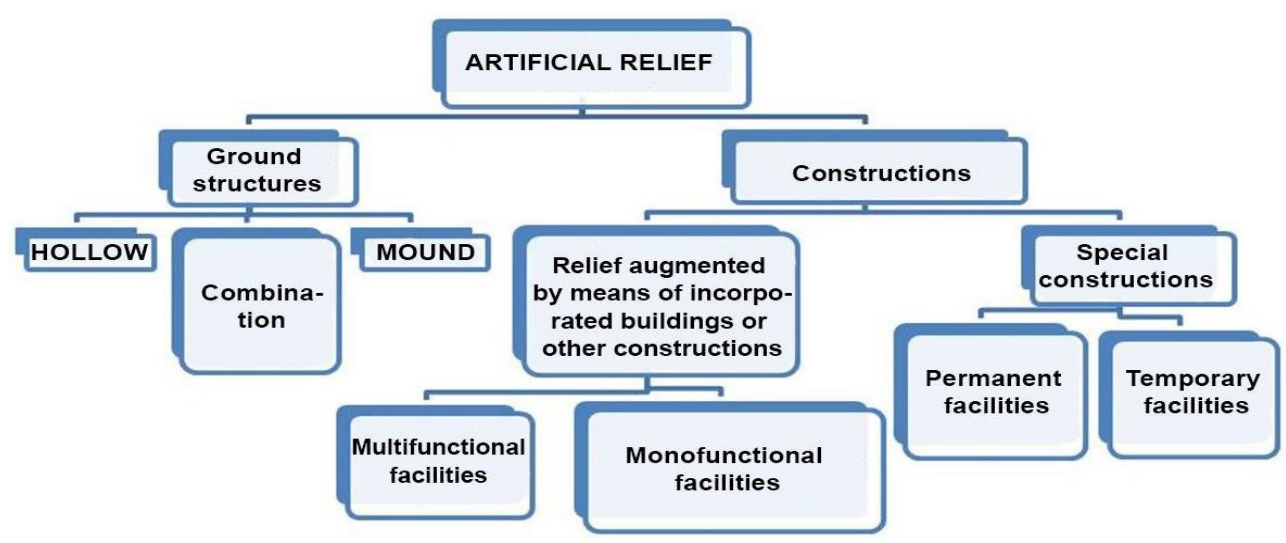

Fig. 1: Typology of Relief Alteration Methods for Recreational and Sports Facilities.

At the first level, it is suggested to divide the facilities by the method of formation - into ground structures and constructions. The structures are grouped by relief type - mounds, hollows or their combination. The second branch suggests distinction between relief augmented by incorporated buildings or other constructions and special constructions. There are subgroups by the type of use in the first group: monofunctional facilities, i.e. their basic function is increasing relief height, and multifunctional the ones that have two and more functions. Special structures are numerous; it is suggested to group them by the length of life cycle. Let us illustrate the typology with examples of successfully operating facilities.

\subsection{Ground structures}

Extreme-park Freestyle. In practice there are unexpected design concepts determined by circumstances. For example, the winter recreational extreme-park Freestyle was developed at the boundary of a mined-out quarry in the city of Dzerzhinsky on the border of Moscow and Moscow Oblast (Figure 2).

The total area of the complex is almost $47,000 \mathrm{~m}^{2}$ (of which $15,000 \mathrm{~m}^{2}$ is an earth-fill mound, $17,000 \mathrm{~m}^{2}$ are occupied by the park's infrastructure, and $15,000 \mathrm{~m}^{2}$ is reserved for future facilities). The slope area is $30,000 \mathrm{~m}^{2}$; the number of tracks is 6 ; slope length: children track $-50 \mathrm{~m}$, main track $-300 \mathrm{~m}$; capacity up to 300 people at a time; adjoining water surface - approximately $200,000 \mathrm{~m}^{2}$ [9].

The recreational and sports centre Sorochany was established in 2001 in the valley of the Yakhroma river $40 \mathrm{~km}$ away from Moscow. It covers the territory of approximately 324 ha $\left(3,240,000 \mathrm{~m}^{2}\right)$. The centre is part of the urban sprawl formed along the Savyolovsky suburban direction of the Moscow Railway and the Moscow Canal. A new artificial soil structure is raised in the existing slope. After the construction the area of the artificial hill made up almost 86 ha $\left(860,000 \mathrm{~m}^{2}\right)$, and the amount of the filled soil was approximately 2 million $\mathrm{m}^{3}$.

The line of the natural relief can be seen in Fig. 3 outlined by the trees on the border between the natural and the man-made slopes. The territory of the Sorochany centre (Kurovo, Dmitrovsky district) is typical for the Moscow region with its overwatered soil. The artificial hill consists mostly of sandstone, partially sandy loam, inhomogeneous, with multiple brick and concrete fragments, gravel, construction debris and layers of clay loam. It has little moisture and different density. The geological composition of the field was defined in five sections including the zones of protective works against erosion.

Very early it was noticed that the slopes were eroding, therefore, in 2001-2006 special works were carried out to reinforce the slopes with various materials and methods (Table 1). The centre was under constant monitoring of the specialists of Moscow University of Civil Engineering [2], [10]. 


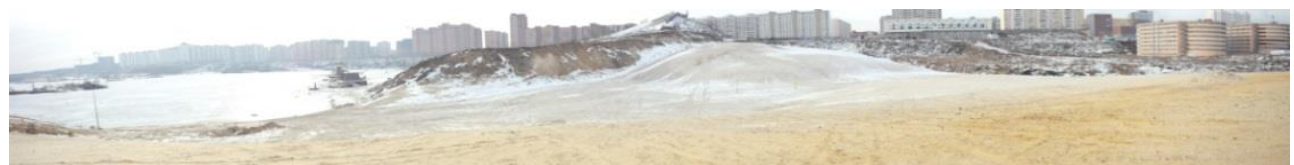

Fig. 2: General View of the Recreational Territory in Dzerzhinsky, Moscow Oblast (Authors' Photo, spring, 2014)

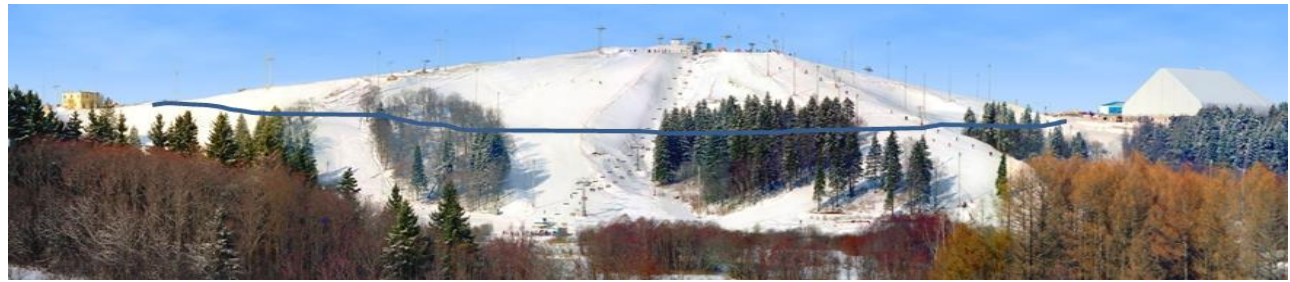

Fig. 3: Recreational and Sports Centre Sorochany, Moscow Oblast.

\begin{tabular}{llll}
\hline$\#$ & Type of reinforcement & Used since & Reinforced area, thousand m ${ }^{2}$ \\
\hline 1 & Wooden constructions & $2001-2002$ & 18.8 \\
2 & Biomats & 2004 & 6.03 \\
3 & MacMat geomats & 2004 & 10.6 \\
4 & Gabion constructions & 2004 & 4.7 \\
5 & Geocells Prudon-494 & 2005 & 16.6 \\
\hline
\end{tabular}

(A)

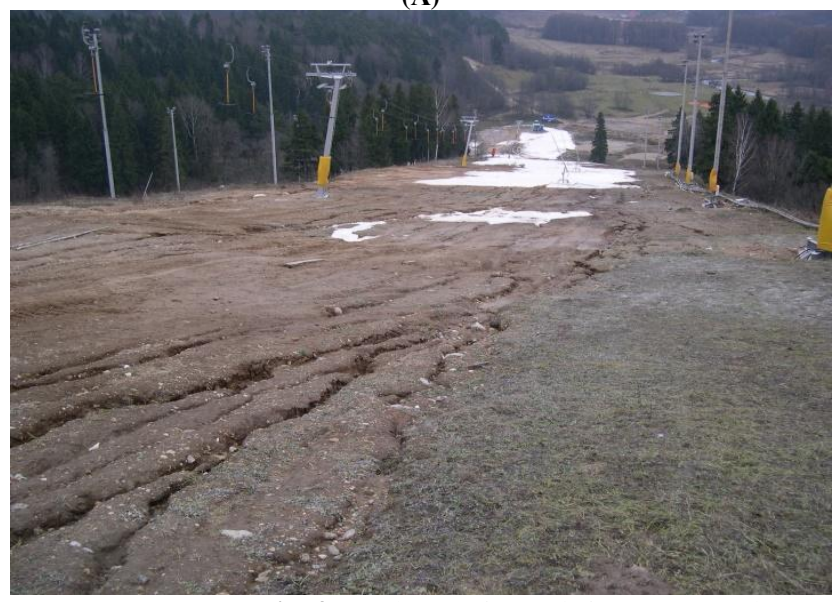

Fig. 4: A) Slope Before Reinforcement Works, October 2006; B) the Territory of Tubing-Park, May 2007.

(A)

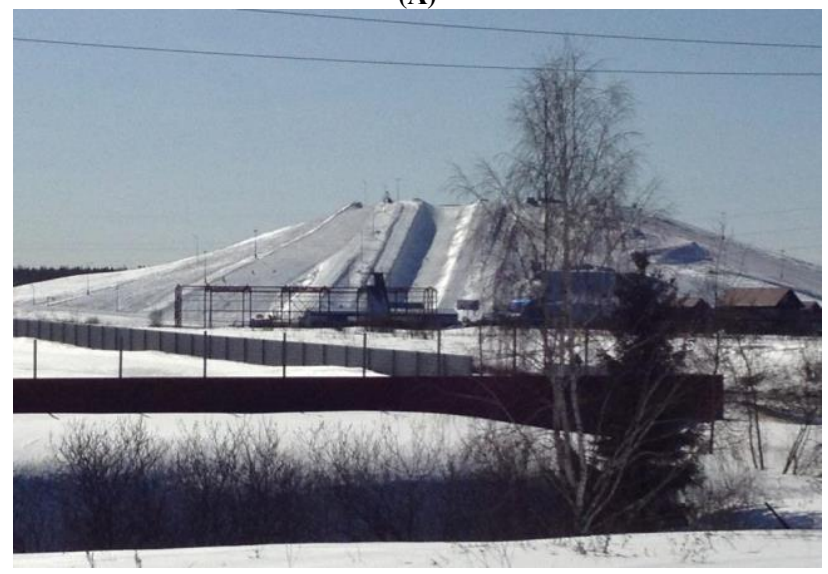

(B)

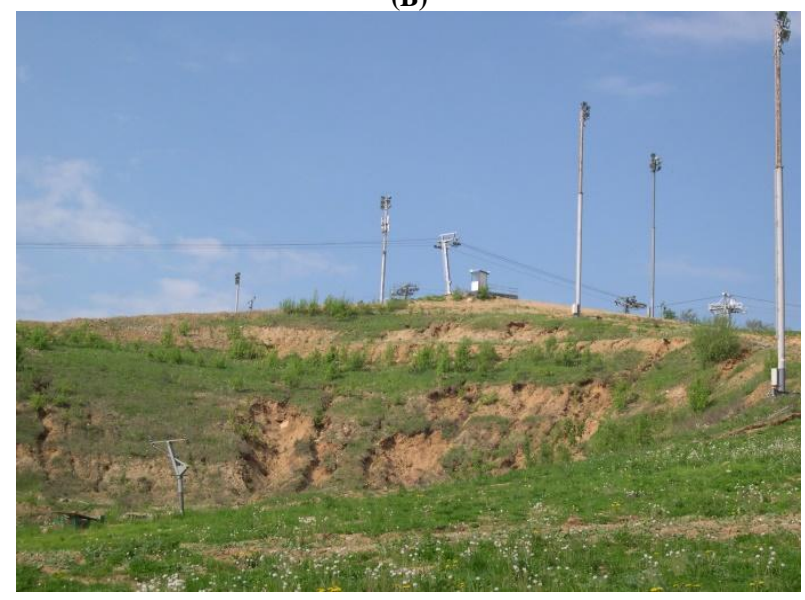

(B)

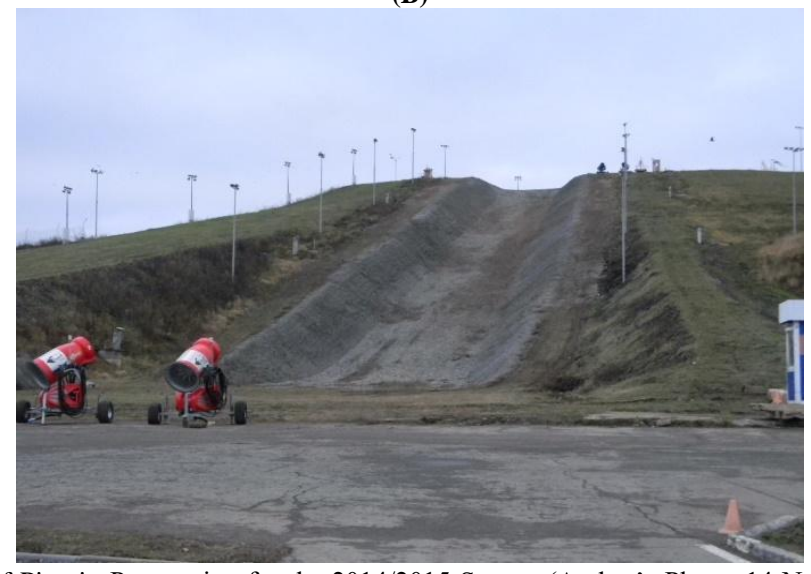

Fig. 5: Novo-Peredelkino Ski Resort, New Moscow. A) General View; B) Half Pipe in Preparation for the 2014/2015 Season (Author's Photo, 14 November 2015).

Over five years of constant reinforcement works, the erosion processes were stopped on all sites providing safe support for chairlift towers. Not only the destruction of the slopes was blocked but also their aesthetic qualities were increased and the secondary landscape became stable. Nowadays, only archive photos can reaveal what complicated and uncontrolled processes were taking place on the territory of the centre.

The Novo-Peredelkino ski resort is an artificial construction which started operating in 2002. The requred construction materials - soils - were brought in from the major Moscow building sites of 1999-2000: Moskva-City, Moscow Ring Road, Third Ring Road junctions, Kutuzovskaya and Leninskiy Prospekt subway stations. When the soils transported to Novo-Peredelkino (New Moscow) amounted to 1.8 million $\mathrm{m}^{3}$, it was decided to build there a new permanent ski resort. At that time no one could even suppose how many issues the designers and builders would have to deal with to achieve the aim. 
In 2002, systematic transformation of the shapeless mass unto a ski slope was begun. Over a year a special sports facility was developed. The works were accompanied by multiple slides caused by the structure of the soils. Despite the engineering and organizational issues, the resort started operating and is currently successful (Fig. 5A).

Characteristics of the facility: the slope is 50 meters high, it has 3 professional ski-jumps, 4 tracks of various difficulty levels up to 200 meters long equipped with chairlifts for adults and children. It boasts Moscow's only half pipe, big air, spine and rail park. The half pipe is the largest and most important part of the complex. It took the longest time to be built and it has been operating for the longest time, too. It is an on-ground chute with gabion-reinforced sides (Fig. 5B).

\subsection{Special permanent structures}

The ski resort Snezhkom is the only one in Russia all-season mountain skiing complex which started operating in 2008. The complex is located in Pavshinskaya Poyma district, the city of Krasnogorsk. Its total area is $24,000 \mathrm{~m}^{2}$, elevation difference is 68 $\mathrm{m}$, slope length $400 \mathrm{~m}$. It took 18,000 tons of steel constructions to build the skiing complex. It is located on the boundary of Moscow and Moscow Oblast, next to a highway (Fig. 6), which provides convenient entrance to the territory with a separate multi-storey car park.

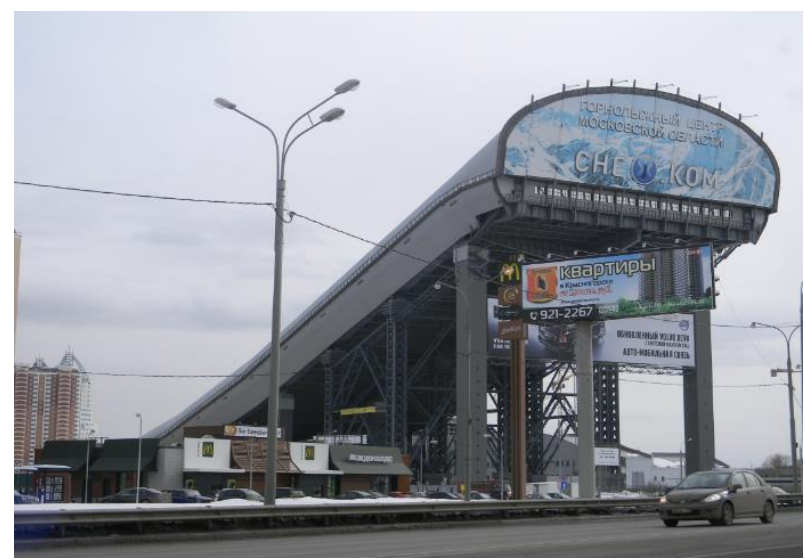

Fig. 6: Snezhkom Complex, Krasnogorsk, Moscow Oblast. View from the Highway (Authors' Photo, spring 2014).

An unconventional architectural and engineering solution of the complex is its external surface, which is made in the shape of an ellipsis. It shields off cold air blasts and aerodynamic effects which usually complicate the maintenance of a facility, and protects the complex against solar radiance as well. About 300 skiers and snowboarders can slide down the slopes at a time. There are two tracks with bar- and chair lifts. The complex includes restaurants, shops, a children's room, sports gear hire, changing rooms, an aqua area, a skating-rink, a fitness centre, a laser shooting room, etc.

\subsection{Special temporary facilities}

In all countries of the world winter sports competitions (snowboarding, freestyle skiing, freestyle motocross) are held on natural slopes, but Moscow is the only city where sportsmen compete on an artificial ramp. Artificial ski slopes with a complete range of ski resorts have been constructed in the capital since 2008. These constructions are unique. The temporary facilities are moved from Luzhniki to Gorky Park, to Vorobyovy Gory, to Kosygin Street, to the All-Russian Exhibition Centre or to Krylatskoe [11]. The construction of sports ramps - large-scale temporary facilities for winter sports - has became a usual practice for the capital with its complicated existing urban infrastructure. A new format of competitions - 'city event' - combines sport and show.
In the season of 2014/2015, the district of Krylatskoe was chosen as a place for constructing a new ramp. The vast area of the Olympic Rowing Channel and its infrastructure allowed for a harmonious fit of an openwork ramp (dimensions of $50 \mathrm{~m} / 30 \mathrm{~m} / 140 \mathrm{~m}$, speeding angle of $24^{0}$ ), which became an architectural dominant of the space. A specific feature of that season was that, unlike all previous years, the structure was not entirely disassembled upon the end of competitions [12]. In summer, only a small part of the facility was dismantled, the greater part was retained (Fig. 7). It allowed saving time and money for erecting the most labour-consuming part of the structure in the new seasons.

(A)

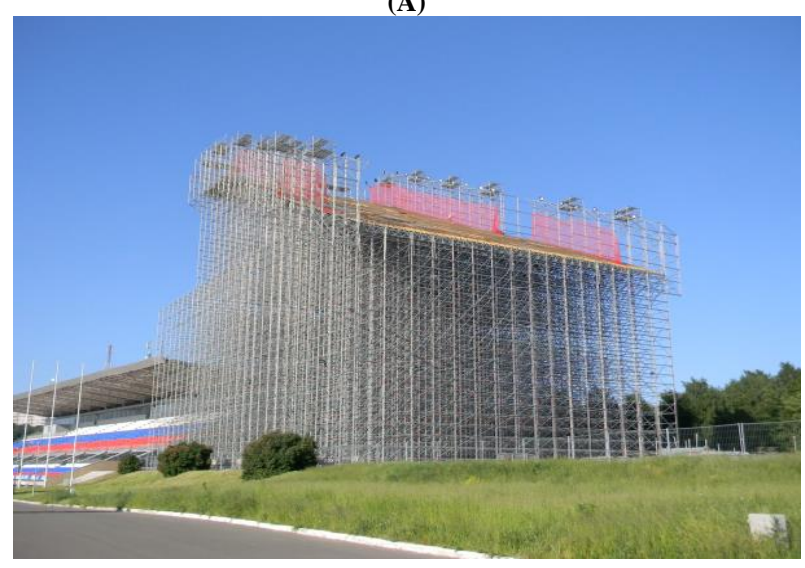

(B)

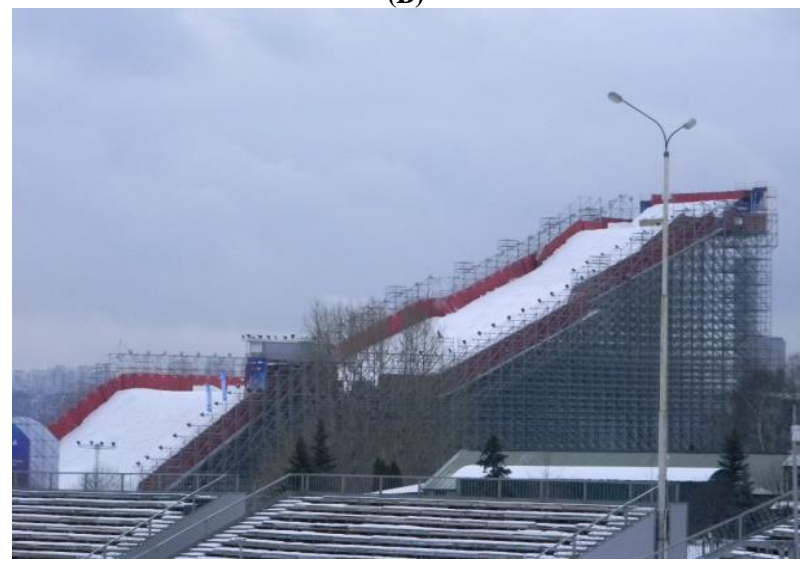

Fig. 4: Sports Ramp in Krylatskoe, Moscow: A) Summer of 2015; B) winter of 2015/2016 (Authors' Photos).

In the new season of 2015/2016 the ramp's form was changed with a steep upper starting section and flat outrun area (Fig. 7B). The object is a good example of a sound engineering and economic approach which combined several techniques: keeping the basic part of the structure and changing the facility's architectural look by means of temporary sections.

In the winter of 2015/2016 the facility was regularly used: the main winter extreme sports event Grand Prix de Russie was held in January, a stage of Freestyle Skiing World Cup in February. Over 35,000 spectators attended the competitions including the president of Russia V.V. Putin.

The artificial snow was produced by two snow machines with a capacity of up to $10 \mathrm{~m}^{3} / \mathrm{h}$. The snow was produced at the foot of the ramp and hoisted with a tower crane onto the slope where experienced mountain skiers spread and groomed it with ratracks. To prevent snow slides and decrease the weight of the construction, hay biomats were placed on the hard base of bakelite sheets (Fig. 8A). Hay biomats were also used in construction of freestyle skiing jumps. The scope of the construction works can be assessed from the top landing (Fig. 8B).

The ski ramp was used in 2016/2017 for World Cup stages in freestyle skiing, mogul and snowboarding. The construction of the 
ramp was designed and built in such a way that between the World Cup starts in snowboarding (30 January - PGS, 13 February freestyle and 5 March - dual mogul) only minimal preparation was required. A large team of professionals works on adapting the slope for various competitions; they control the equipment, electricity supply, heating systems as well as provide comfort and convenience for sportsmen, spectators and umpires, organize shows, ensure safety, etc.

Tubing slope. The number of temporary winter facilities and their locations is growing, however, there are facilities constructed on the same place on a regular basis. The largest Russian temporary artificial monofunctional facility is a children's snowtubing track $(88 \mathrm{~m} / 10 \mathrm{~m} / 11.4 \mathrm{~m})$ (Fig. 9A). It was built for the sixth time in the season of 2015/2016 on the territory of Moscow Sokolniki Park. It is nicknamed The Gorka. The temporary facility is located within the boundaries of a highway in the park. This location is explained by the fact that Sokolniki Park enters Losiny Ostrov national park wherein the construction of any facilities is forbidden.

The frame of the slope is modular wedge scaffolds used for building many temporary facilities, including sport ramps. Tubing track design solution is shown in Figure 5. The frame structure includes steel vertical elements, cross-bars, diagonals, lift jacks (Fig. 10A). The system of wedge scaffolds saves money and time and allows making fail-safe joints. Bakelite veneer, timber, and fixing arrangements are used as additional materials; the total weight of the construction is 60 tons.

Every year The Gorka is different [13], [14]. In the first three years the slope had a lift, which later was rejected. By the types of materials, the construction consists mostly of reusable metal scaffolds (50 tons), while wooden elements make up for only 10 tons. But the volumes of materials in transportation are almost equal.
(A)

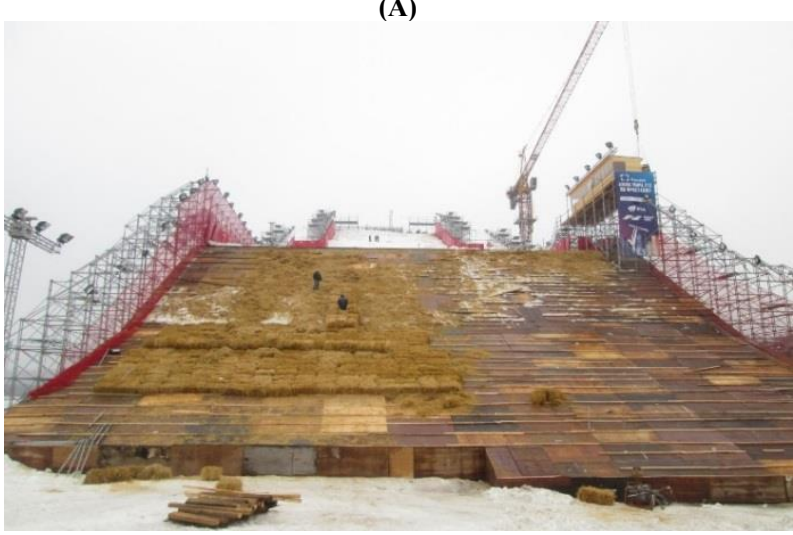

(B)

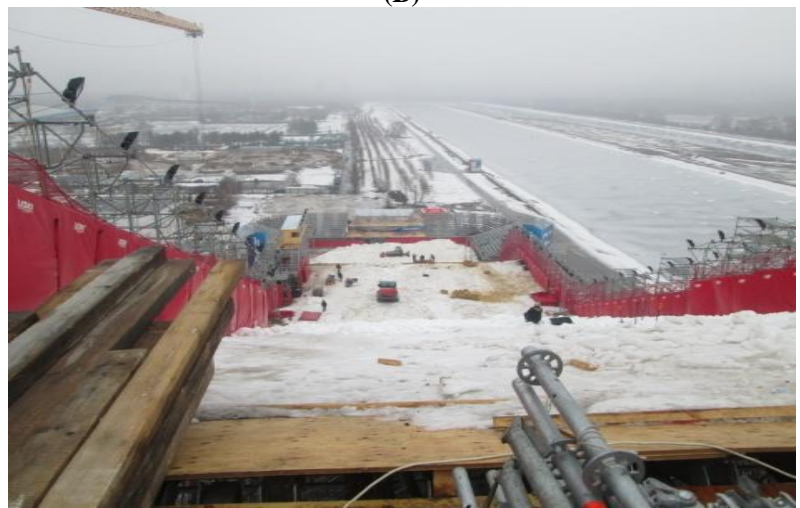

Fig. 8: Construction of the Ramp in 2015/2016: A) Laying the Base; B) Top Landing View (Authors' Photo).

(A)

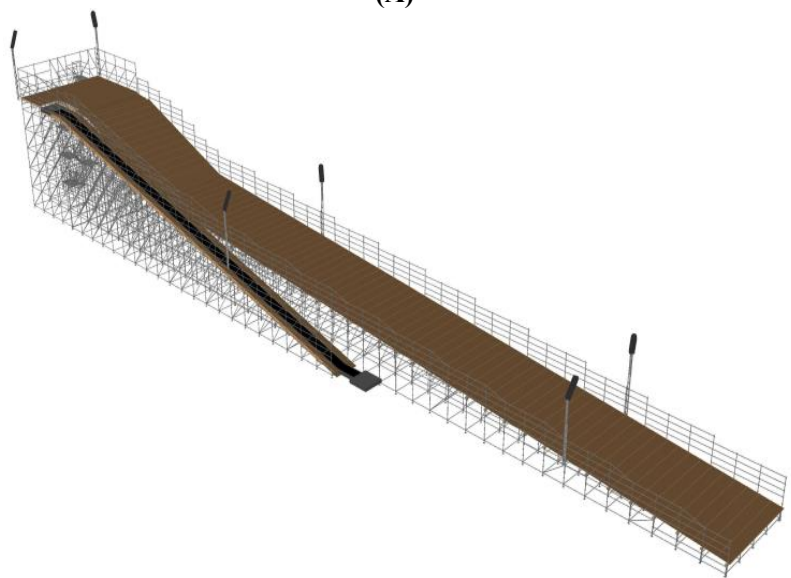

(B)

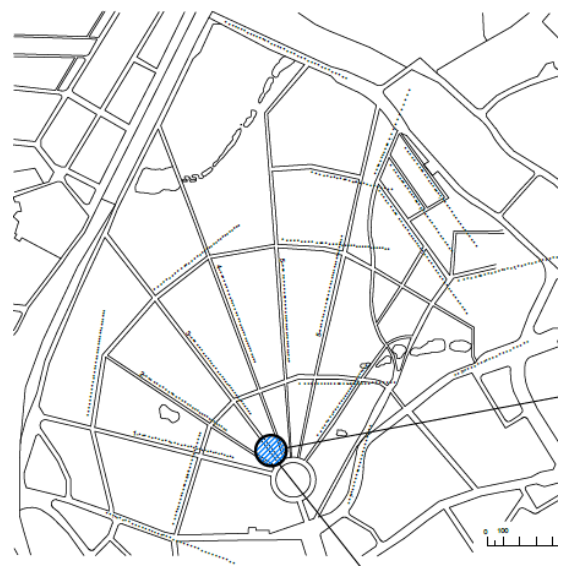

Fig. 9: The Gorka. Sokolniki Park, Moscow: A) Project of the 2014/2015 Season; B) Location in the Park.

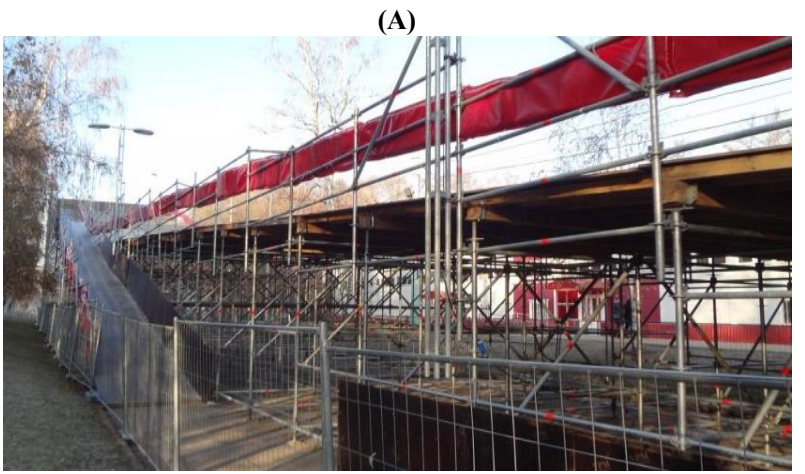

(B)

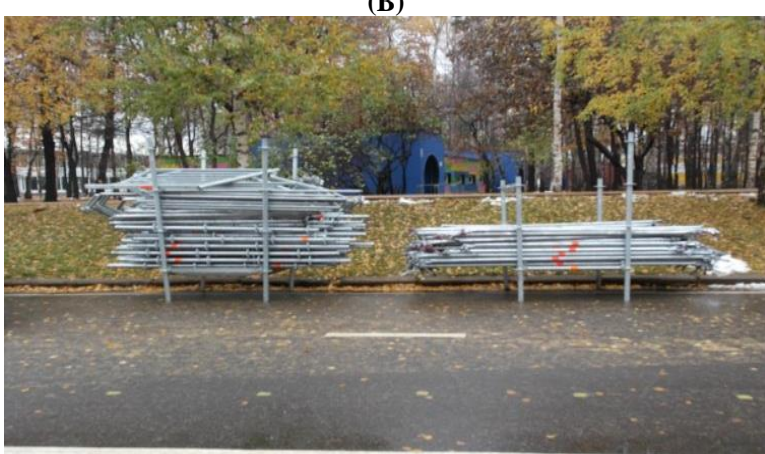

Fig. 10: Construction of the Gorka: A) Structure Erection; B) Temporary Storage of Frame Parts (Authors' Photo, Autumn 2014).

The construction is assembled by 2-4 workers over 9 days. The works are performed 'just-in-time'; there is a small in-situ stock of frame parts (Fig. 10B). Dismantling is performed by the same team of workers over 4-5 days, and the materials are immediately transported away. 
Snowboarding 'city spot'. In restrained urban conditions it is impossible to build large-scale constructions. Therefore, temporary local sports facilities - city spots - are becoming increasingly popular. An example is jibbing spots which do not require large areas but attract a lot of young people [14].
Setting up a sports facility in a city requires a special permission for sports and recreational activity. Usually city spots are located in central city parks (Fig. 11) which already have all engineering systems (water and energy sullies), vehicular accesses, parking places, equipment storage facilities, etc. [13].

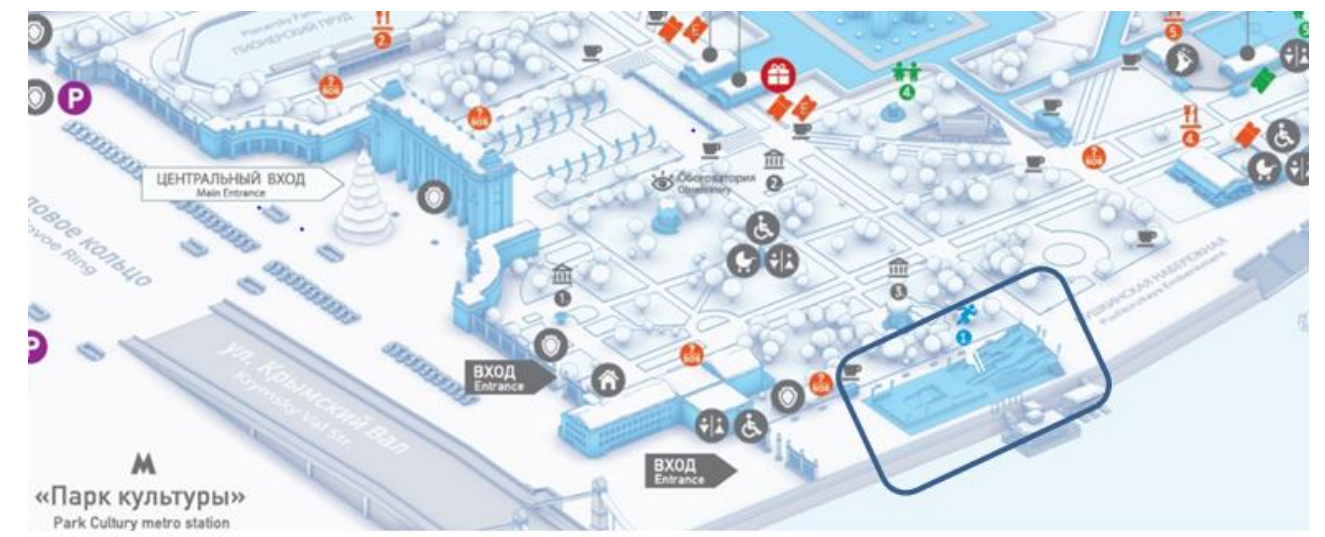

Fig. 11: Location of Gorky City Spot Snowboarding Park in Gorky Park, Moscow.

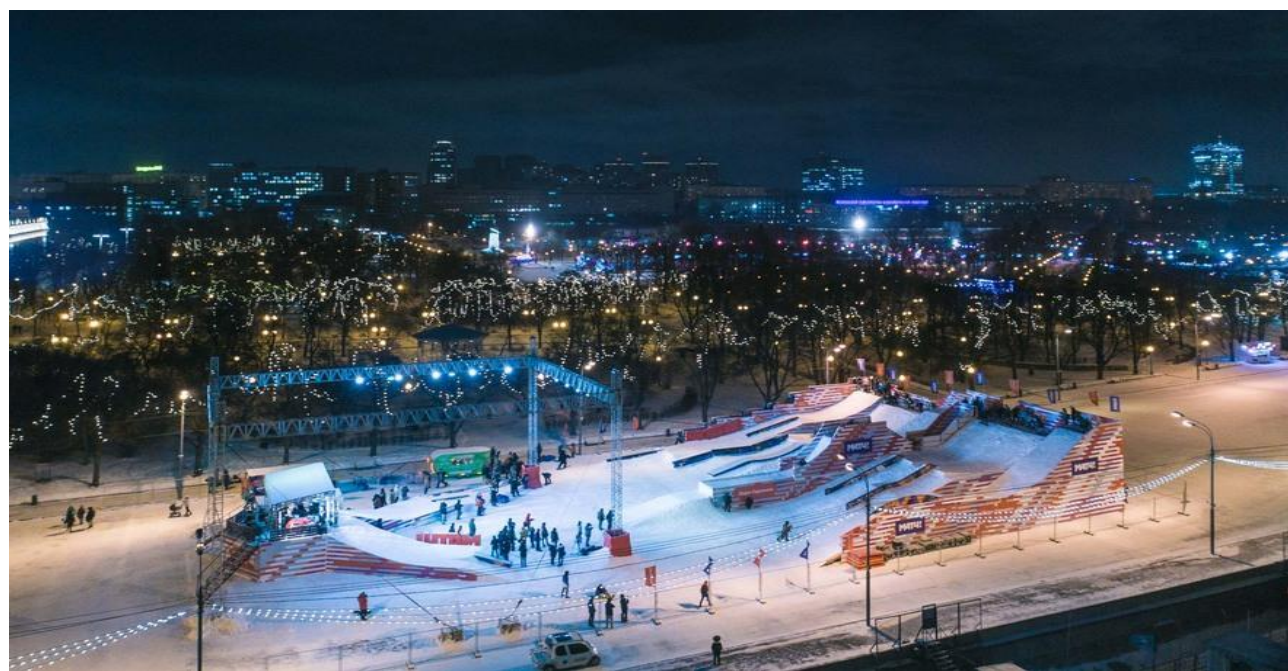

Fig. 12: General View of the 2016/2017 City Spot (Photo Publicly Available at: Http://Doskimag.Ru/Posts/4350-V-Parke-Gorkogo-Otkrylsya-City-Spot).

Table 2: City Spot Characteristics

\begin{tabular}{lll}
\hline Season & $\begin{array}{l}\text { Size: length/width/height/snow- } \\
\text { covered area, } \mathrm{m}^{2}\end{array}$ & Description \\
\hline $2012 / 2013$ & $110 / 4.5 / 16 / 150$ & 2 zones: Pro and Beginner; only the Pro zone includes snowboarding features \\
$2013 / 2014$ & $100 / 5.5 / 25 / 200$ & 3 zones: Pro, Beginner and Amateur \\
$2014 / 2015$ & $120 / 6.5 / 25 / 350$ & 4 zones: Pro, Beginner, Amateur, and Riglet Park for kids \\
$2015 / 2016$ & The facility was not erected & \\
$2016 / 2017$ & 3 zones: Beginner, Amateur, Pro; the features are changed during the season \\
\hline
\end{tabular}

Moscow's Gorky Park has a vast modern snowboarding ground with the world's largest artificial slope and a number of objects for jibbing. Every year the city spot has new special characteristics (Table 2).

All parks have special snowboarding features — rails and boxes of various forms and shapes: waves, gaped multi-radius three or four stepped rainbows, sometimes incredible hybrids of s-shaped slide box and wave, parapets, pipes, props, wall rides, etc. Rails are made of welded metal sections or other material in the form of a circle, square or an oval with a diameter of $0.05-0.30 \mathrm{~m}$; it has a complicated configuration (Fig. 13A). Boxes are three dimensional structures consisting of 2 or more rails rigidly fixed to each other at intervals from $0.1 \mathrm{~m}$ to $0.3 \mathrm{~m}$ (Fig. 13B). A gas pipe is a pipe on an inclined surface; the length and inclination can differ (Fig. 13C). There are many types of rails and boxes, in the special terminology they are called 'features'.

Monitoring the snowboarding grounds of Gorky Park shows that the periods of assembling and dismantling are similar - 10-14 days. The period of operation depends on availability of snow and temperature; the highest attendance predictably falls on weekends and holidays. There is no artificial snow system; the snow is brought from the Park's skating rink. Therefore, double economy is achieved - energy saving on snow machines and money saving on snow disposal.

In $2016 / 2017$, the city spot included three slopes 2.5 to 6 meters long and 21 features for jibbing. The shapes of the features were changed during the season, which was an innovation since in the previous seasons their shapes stayed the same all year. As before, this season's spot was fitted with a warm changing room. The entrance was free.

Action sports facilities. In March 2014, the All-Russian Exhibition Centre in Moscow opened a rare sports facility - an imitation of a helicopter on whose blade snowboarding professionals demonstrated their skills (Fig. 14). The 6.5 meters tall and 10 meters long construction was a cross between a rail and a box in the form of a helicopter. 
(A)

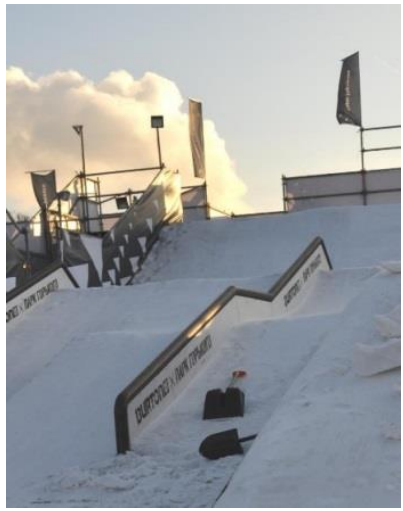

(B)

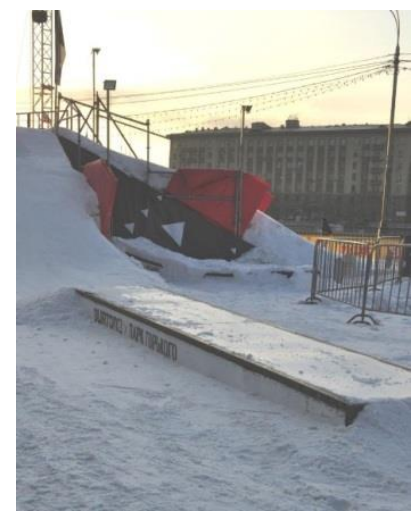

(C)

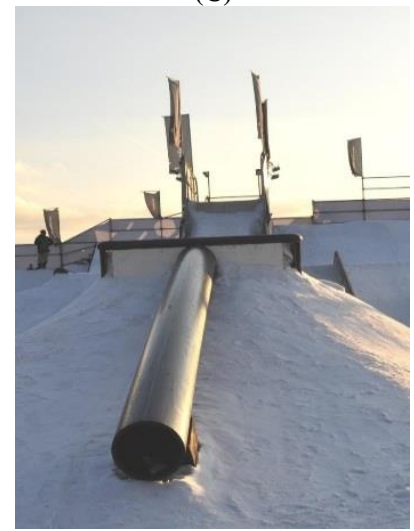

Fig. 13: Snowboarding Features of Gorky Park: A) Rail; B) Box; C) Gas Pipe (Authors’ Photo, January 2015).

Table 3: Life Cycle of Gorky Park’s City Spot

\begin{tabular}{|c|c|c|c|c|c|}
\hline & $\begin{array}{l}\text { Number of days } \\
2012 / 2013\end{array}$ & $2013 / 2014$ & $2014 / 2015$ & $2015 / 2016$ & $2016 / 2017$ \\
\hline Assembling & 14 & 13 & 14 & & 15 \\
\hline Operation & 93 & 85 & 94 & Was not erected & $13.12-08.03(86)$ \\
\hline Dismantling & 12 & 11 & 10 & & *under approval \\
\hline
\end{tabular}

(A)

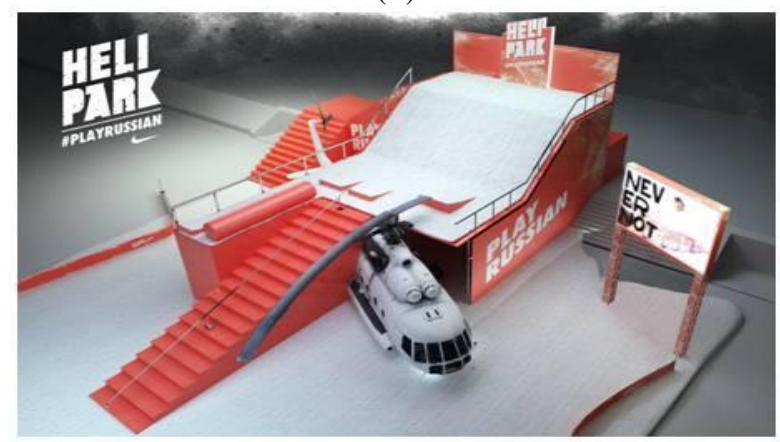

(B)

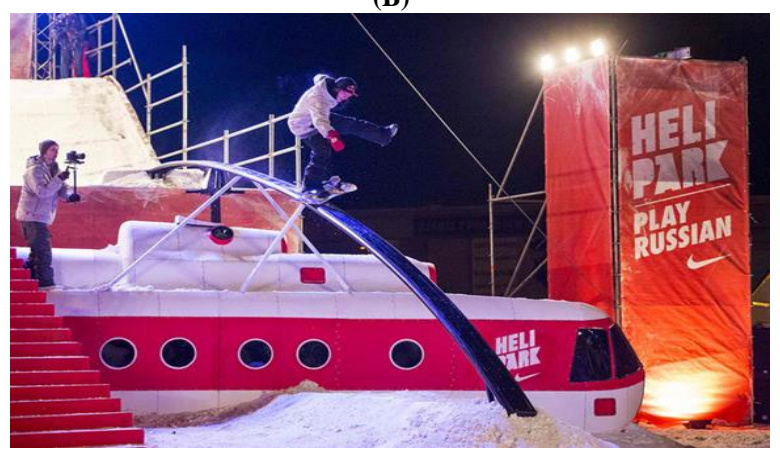

Fig. 14: Snowboarding Facilities in Moscow. February 2014 [7].

The mock-up of a helicopter stood in Promyshlennost Square in the Exhibition Centre next to the legendary Vostok rocket for less than a week, but it excited snowboarders and spectators. It created a precedent for constructing unconventional objects for city events.

Ice cross downhill tracks. In the beginning of 2000, a new kind of sport appeared (Red Bull Crashed Ice) and the requirements for building downhill skating tracks were developed. The competition required an ice track - a linear structure about $5 \mathrm{~m}$ wide and 300-600 m long consisting of a frame (wooden or metal), ice layer no less than $10 \mathrm{~cm}$, and safety boards. The rack needs to include an obligatory set of obstacles: three barriers, a speed section, a bend, a serpentine labyrinth and a gate under which a sportsman needs to pass touching his breast on the ice. For every new competition, architects think of new unordinary solutions using even nearby historical buildings [6].

In 2016/2017 new ice cross downhill facilities were built in Russia. This year sportsmen competed on a natural slope in Leonid Tyagachev's ski club in Moscow Oblast. The competition was in the framework of Riders Cup, which differs considerably from the main tournament. Although it was a supplementary competition, the track was laid, and its construction enlarged the experience of building new sports facilities.

Park Pobedy, Moscow, in 2016/2017 became the ground for the Ice Moscow: Traveling around Russia festival. On the central square of Ice Moscow Park, the Moscow Kremlin was erected decorated with five towers with ice slide cascades of sparkling ice. The Spasskaya tower of the Kremlin was the tallest $(10 \mathrm{~m})$, the first ice object of such size in Moscow (Fig. 16). The top of the slides was designed as a fairy tale castle; there were three slides of $140 \mathrm{~m}, 90 \mathrm{~m}$ and a special slide for children of $45 \mathrm{~m}$. the longer ones were located in the 'Sochi Olympic Games' zone. The slides and the castle were decorated with neon lights. Around the slides there were smaller sculptures symbolizing popular fairy tales and holidays. Six more slides started from 'the Kremlin wall' in the centre of the park and went down to the sculptures symbolizing Russian cities. The main building material for all sculptures was natural ice from the clearest waters of Russia.

(A)

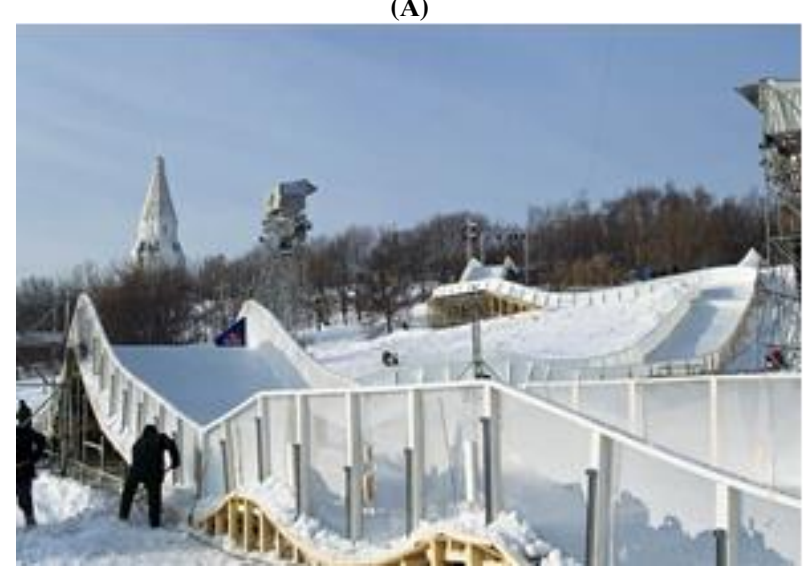


(B)

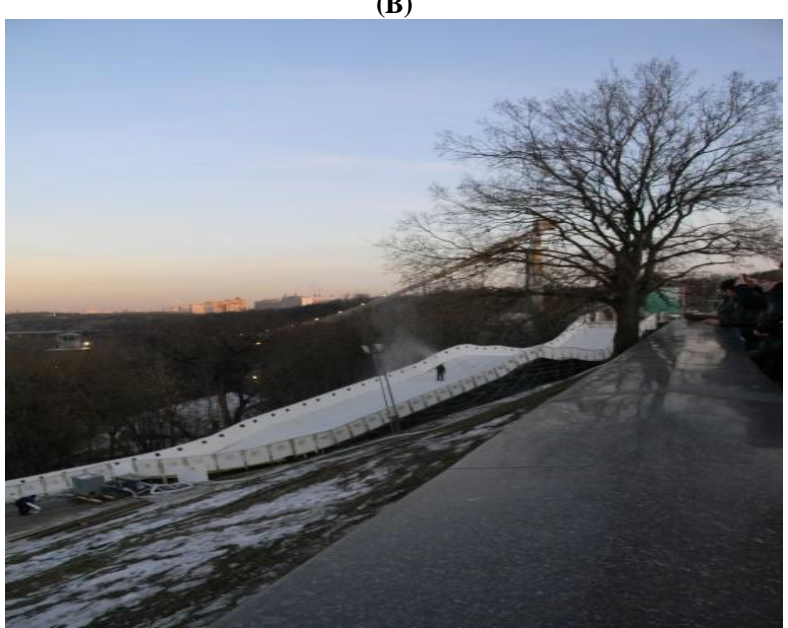

Fig. 15: Downhill Skating Tracks. Moscow: A) Construction in Kolomenskoye Park; B) Vorobievy Gory (Authors' Photo, February 2014).

(A)

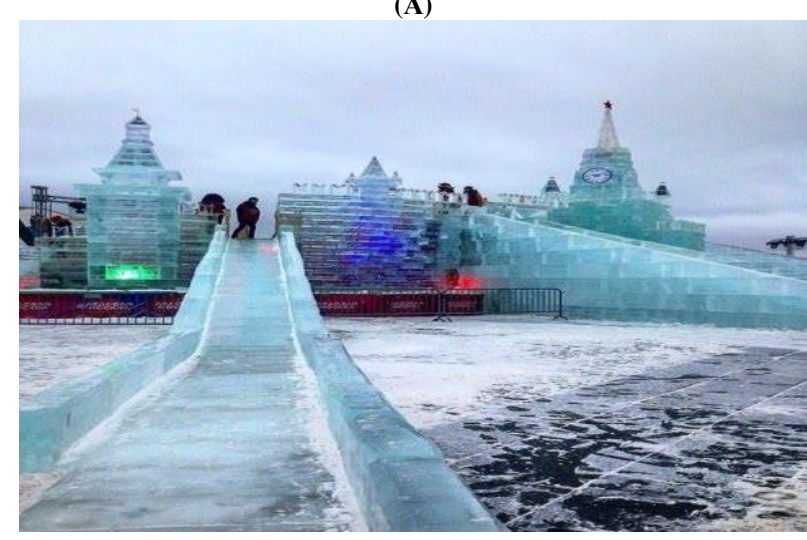

(B)

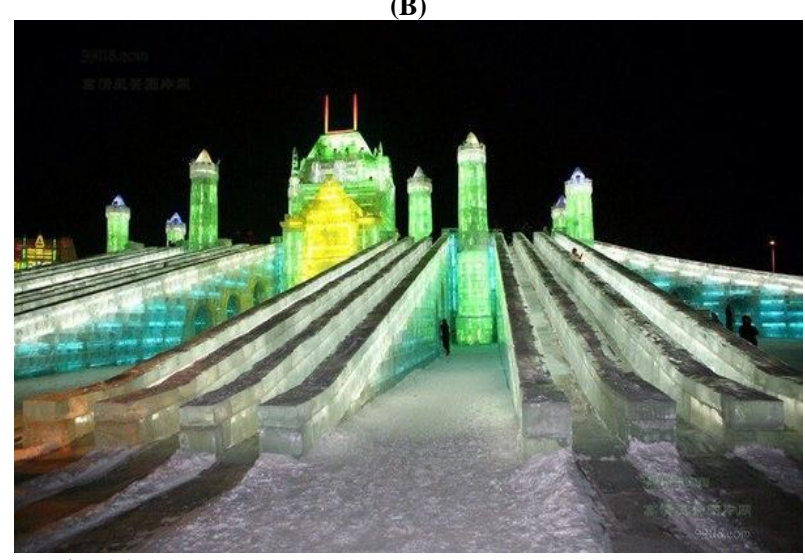

Fig. 16: Ice Constructions in Park Pobedy. Moscow, 2016/2017.

These examples of temporary demonstrate that they are various, easily adaptable to existing environment, functional, ecologically sound and economically feasible.

\subsection{Relief augmented by means of incorporated build- ings or other constructions}

The Kant ski resort is a unique Moscow phenomenon located in close proximity to the Nagornaya metro station. When approaching the resort, you get the impression you are going the wrong way, since according to common ideas there could be not recreation facility in a former industrial area adjacent to a very busy highway Varshavskoe Shosse. Kant was opened in 1998; since then, the industrial area and the territory of an abandoned ravine have been developed. When building the complex two main methods of relief change were used: facility construction and ground dumping.
Nowadays Kant includes a number of slopes of different complexity level over $3.5 \mathrm{~km}$ in length and with elevation difference of up to $55 \mathrm{~m}$. It clearly fits into the district's territory and attracts many locals. Currently it is an all-season object which consists of 17 slopes, a snow park, a tubing park, a skating-rink, a cross-country ski track, a few bicycle tracks, a gym, indoor tennis courts, tramps, a SkyTec mountain skiing simulator and many other things. There is an artificial snowing system, a lighting system, lifts, etc. The main building (Fig. 17) fulfills several tasks: it significantly raises the existing elevations and functions as an administrative, training and sports center.
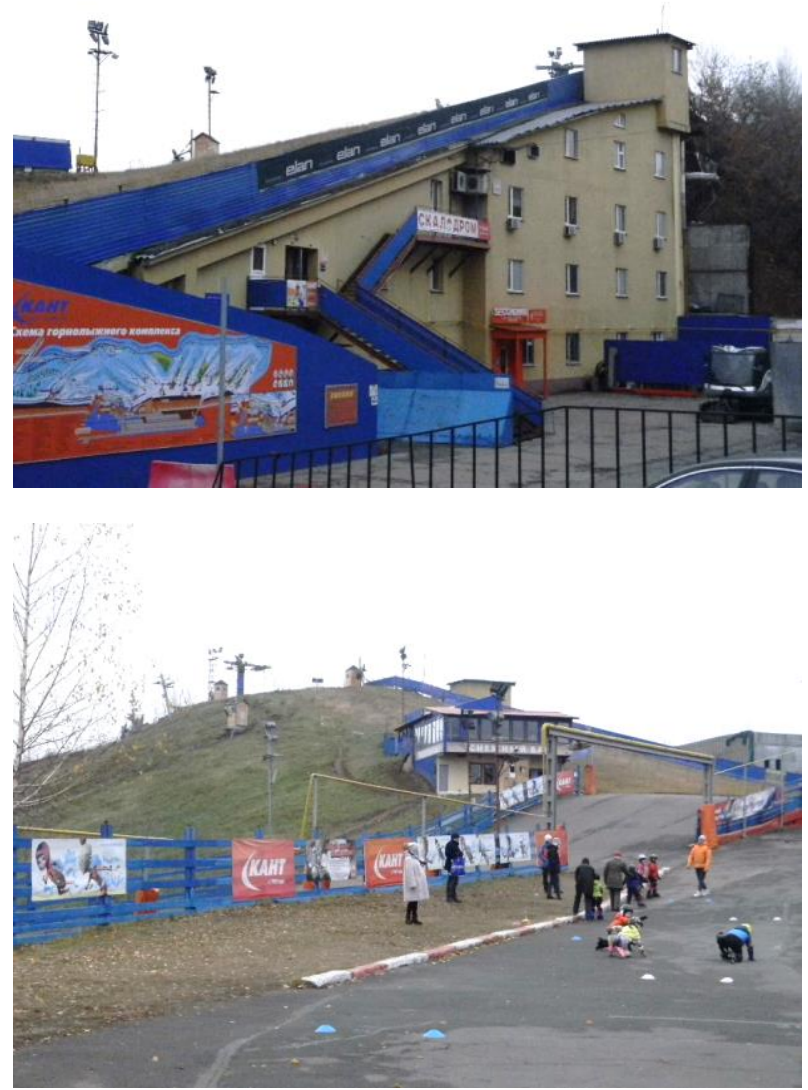

Fig. 17: Kant Ski Resort, Moscow. Main Building (Authors' Photo, December 2015).

All the year round children from 3 years and older are trained in snowboarding and mountain skiing, notably, on the only asphalted slope in the capital. The $260 \mathrm{~m}$ long track with smooth even coating, sharp turns and a lift is also suitable for longboarding. In the halls located in the main building, children train on a tramp and a rock-climbing wall; there are changing rooms, coach rooms, showers and toilets. A barrier between the former industrial area and the Kotovka and Nagorny residential areas created when reconstructing the territory became the base of the recreational system [3], [7].

Another example of increasing natural elevations is the Yakhroma ski resort in Moscow Oblast. The slope here is additional functions. Two tracks have a common start on the roof of a restaurant (Fig. 18A).taking into account all erected constructions, the length of the tracks is $250 \mathrm{~m}$, and the elevation difference is $50 \mathrm{~m}$. One of the tracks is wide and even with a considerable drop in the top part and a smooth outrun; the other has a sharp drop at the start. Both are meant for well-trained sportsmen; they are used for training and competitions in slalom, all-Russian children's competitions, etc.

A tubing facility in the Muzeon art park in Moscow is an original construction beginning on the roof of a café (Fig. 18B). The length of the wooden slope is 20 meters; there is a parallel staircase; the gear rent is under the slope. In the winter it functions as a tubing 
track, in the summer it is used by skate-boarders and bikers. From the roof of the café there is a beautiful view on the Moskva river.

(A)

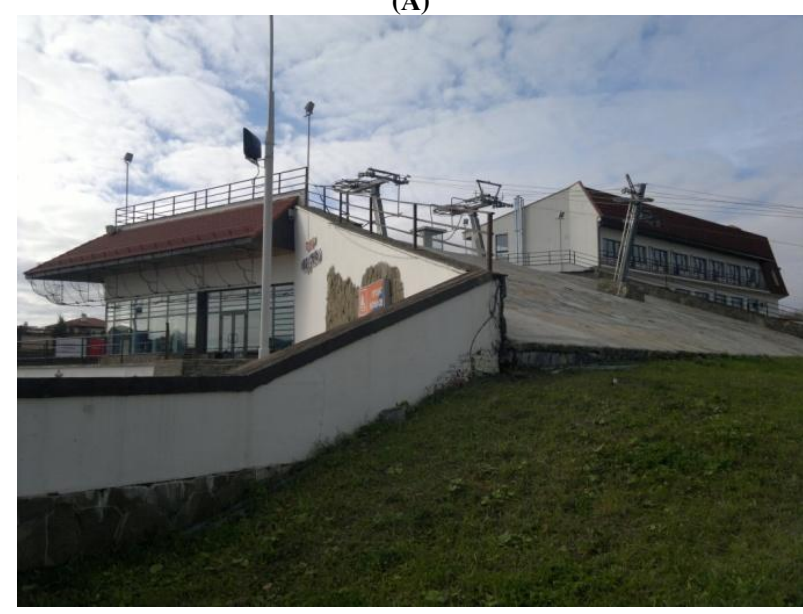

(B)

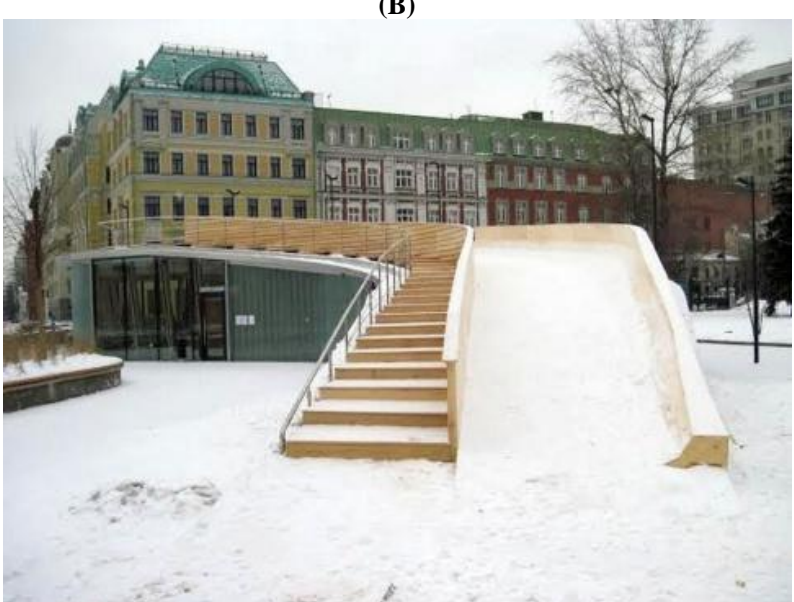

Fig. 18: A) Restaurant of the Yakhroma Ski Resort, Moscow Oblast (Authors' Photo, October 2013; B) Tubing Slope, Muzeon Park, Moscow.

The use of roofs for various purposes is a rarely implemented technique in domestic construction, although in the European architecture the roofs of Novi Sad, Serbia (architect Baron de Vauban), Frankfurt-am-Main's kindergarten (Hundertwasser's projects) [15] are popular objects for recreation and sport [16] The examples shown here demonstrate the beginning of the similar trend in the Russian architecture.
The use of various technical and architectural approaches when building sports and recreation facilities on artificial relief in the territory of Russian cities offers ample opportunities. The described innovative objects have a short history and short period of observation. Therefore, to summarize the information about them, we build attendance graphs according to the type of object (Fig. 19).

Here are some notes to the graphs

City spot. The number of visitors to the youth snowboarding park in Gorky Park increased from 300 people in 2011/2012 to 30,000 people in 2014/2015. In 2015/2016 the facility was not erected due to the political situation, but in 2016/2017 it came into operation again. It explains the gap in the graph.

Ice cross. As a place for holding ice cross downhill competitions Moscow has been chosen three times - in 2011, 2014 and 2017. The graph shows the increase in attendance in the first two years, yet in 2017 the number of visitors was low — only about 200 spectators. It is explained by the status of the competition, the location (Tyagachev ski club, $40 \mathrm{~km}$ away from Moscow) and very cold weather. However, online broadcasting was organized supported by the Megafon cell company. It got 90,000 views nobody had expected such popularity of the new sport.

Ramps. The attendance of sports ramps reached its peak in 2090/2010 and 2011/2012 as in each of these seasons two facilities were built attracting a double number of visitors.

The studies winter sports and recreational facilities differ significantly by the following parameters:

- Type of elements, their arrangement, area size: from small $\left(100 \mathrm{~m}^{2}\right)$ to large ones $\left(200,000 \mathrm{~m}^{2}\right.$ and more);

- Location (within city boundaries or in suburban areas);

- Type of construction materials and structures;

- Life cycle, etc.

Our analysis divides the studied facilities into mass-scale regularly used ones and specialized 'image-building' facilities meant for big events with a large number of spectators. A perfect example of such competitions is the experience of organizing a 'city-event' in Moscow. It required construction of large ramps for a snowboarding and freestyle World Cup stage, aerial skiing, dual slalom, etc. in 2008-2017 [17].

As a result, we developed a classification of facilities based on their purpose and life cycle (Fig. 20). These factors determine the choice of location of the facilities in the city's infrastructure.

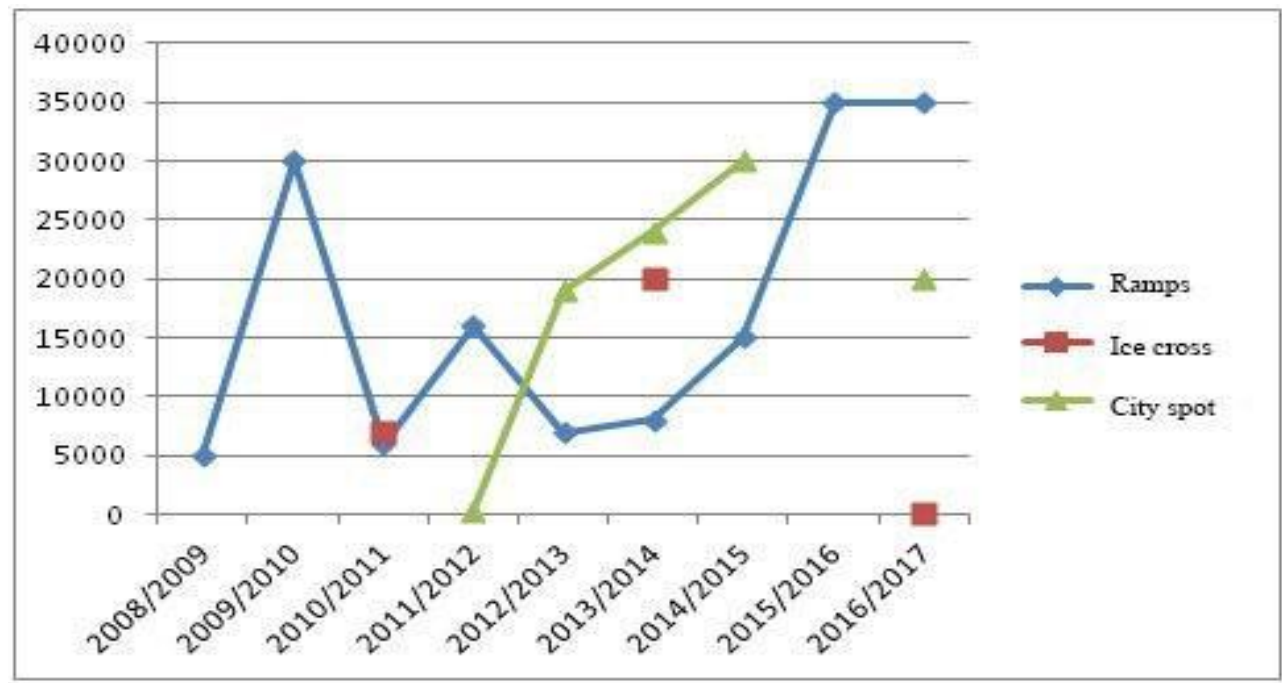

Fig. 19: Number of People Attending Recreation and Sports Facilities. 


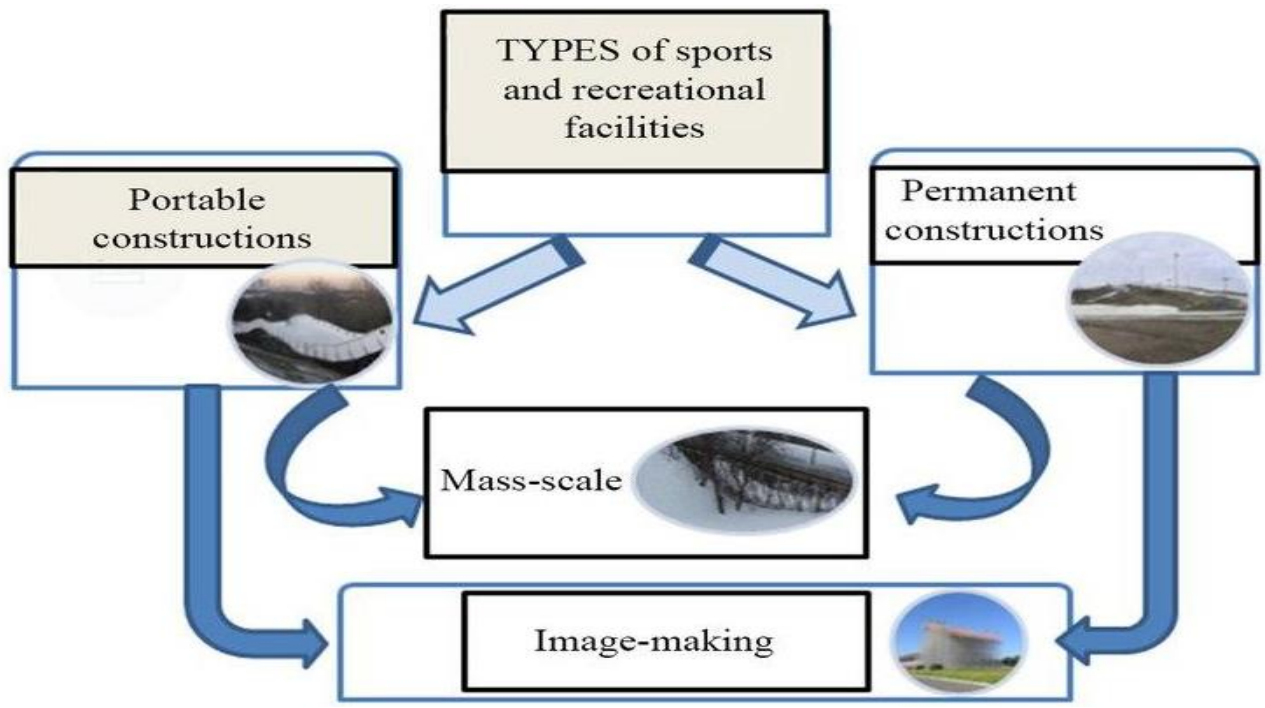

Fig. 20: Classification of Sports Facilities.

Specialized sports facilities create a positive image of the city, attract tourists, popularize new kinds of sport. Therefore, they are located in the territories specially designated for sports events.

\section{Conclusions}

The analysis of construction practice and design decisions implemented in the new generation of city winter recreational and sports facilities on artificial relief allowed suggesting their typology and stating the following conclusions:

1) Recreational and sports facilities on artificial relief for winter sports are socially important in Russia.

2) They are individual and original construction objects which require special architectural and structural solutions for their harmonious inclusion into the existing city environment.

3) Temporary facilities allow experimenting with forms, materials, and equipment; they are easily transformable and, therefore, mobile and socially significant in cities.

4) Temporary portable constructions can be used in the winter period in parks and other recreational zones, thus minimizing the negative effect on natural ecosystems.

\section{References}

[1] IVAnOva, Z., AFOnINA, M. 2016. Setting objectives and developing planning concepts as part of the process of design of Russian urban recreation areas (the social aspect). Procedia Engineering, 165, 1402-1409.

[2] Khodayari Bavil, A., Razavi, S.E., on the thermo-flow behavior in a rectangular channel with skewed circular ribs, Mechanics \& Industry, 18 (2017) 225, https://doi.org/10.1051/meca/2016057.

[3] Afonina, M.I., Burova, M.M. 2012. Analysis of recreational facilities for winter sports in Moscow Metropolitan Area. SWorld, 4(50), 18-23 (in Russian).

[4] ShCHERbinA, E., DANilina, N. 2014. Town planning aspects of designing sustainable urban environment. Bulletin of Irkutsk State Technical University, 11(94), 183-186 (in Russian).

[5] AfONINA, M.I. 2014. Ice cross downhill tracks - objects of innovative construction. Extreme Human Activity, 2(31), 65-69 (in Russian).

[6] AFOnINA, M.I. 2014. Urban Snowparks - fastest growing recreation and sports objects. Ecology of Urban Areas, 4, 149-153 (in Russian).

[7] Shcherbina E.V., Danilina, N.V., Vlasov, D.N. 2015. City planning issues for sustainable development. International Journal of Applied Engineering Research, 10(22), 43131-43138.

[8] Aleshin, A.V., Afonina, M.I. 2014. Objective preconditions of recreation development as part of developed sand pits in the city of Dzerzhinsky in Moscow Oblast. Journal of Voronezh State Technical University, 4(35), 1-6 (in Russian).
[9] ShChERBinA, E., AfoninA, M. 2016. Anti-erosion protection for recreational and sports facilities. MATEC Web of Conferences. DOI: $10.1051 /$ matecconf/20168603012.

[10] AfoninA, M.I., BALABAN V.V. 2013. Innovative Moscow projects of winter sports competitions. Ecology of Urban Areas, 1, 75-79 (in Russian).

[11] Afonina, M.I., Pechalin, P.L. 2015. Dynamics of the development of temporary structures for winter competitions. Scientific Review, 14, 24-28 (in Russian).

[12] Gorlanova, A.A., Balakina, A.E. 2016. Architectural typology of urban snow parks. Scientific Review, 12, 33-37 (in Russian).

[13] Afonina, M.I., Pairavand, M., Sokolova, E.S. 2015. Recreational tubing parks: Planning and constructional decisions. Ecology of Urban Areas, 4, 79-83 (in Russian).

[14] LiVEINTERNET. 2010. Arch-surrealism of Friedensreich Hundertwasser. Accessed 4 February 2016 at http://www.liveinternet.ru/journalshowcomments.php?categ=1\&go $=$ next $\&$ journalid=2058671 \&jpostid=140915439 (in Russian).

[15] Afonina, M.I, Balakina, A.E. 2016. "Green roofs" in historical buildings and fortifications (European experience). Ecology of Urban Areas, 1, 87-90 (in Russian).

[16] AfoninA, M.I., ShCherbinA, E.V. 2016. Spatial and territorial organization of facilities for winter sports (Russian experience). Biospheric compatibility: Human, region, technologies, 2, 29-37 (in Russian).

[17] Khosravi M., Mosaddeghi F., Oveisi, M., khodayari-b, A., Aerodynamic drag reduction of heavy vehicles using append devices by CFD analysis, Journal of Central South University, Volume 22, 2015, pp 4645-4652. 